\title{
Designing Stimulating Environment to Alleviate Orphan Children Psychological Problems
}

\begin{abstract}
Ahed Sobhey Helles ${ }^{1 *}$
${ }^{1}$ Associate Professor, Design and Architectural Theories, Department of Interior Design and Décor, Faculty of Fine Arts, Al-Aqsa University, PALESTINE *Corresponding Author: ah.helles@alaqsa.edu.ps

Citation: Helles, A. S. (2021). Designing Stimulating Environment to Alleviate Orphan Children Psychological Problems. European Journal of Environment and Public Health, 5(2), em0082. https://doi.org/10.21601/ejeph/11057

\begin{tabular}{ll}
\hline ARTICLE INFO & ABSTRACT \\
\cline { 1 - 1 } Received: 3 Mar. 2021 & $\begin{array}{l}\text { Children experience sorrow, anxiety, depression, and lack of support and care after losing their parents. } \\
\text { Accepted: 29 Apr. 2021 }\end{array}$ \\
$\begin{array}{l}\text { Moreover, orphan children in center-based care live in institutional surroundings. Family environment } \\
\text { deprivation and group living can manifest in psychological problems- even in the best programs. This research } \\
\text { aims to elucidate how interior space architecture can instrumentally alleviate children's post parental loss } \\
\text { psychological issues. Relevant literature exploring environmental psychology was reviewed and analyzed. The } \\
\text { researcher proposes a scheme to direct children home design to minimize children's psychological problems, } \\
\text { including detailed descriptions of design interventions. }\end{array}$
\end{tabular}
\end{abstract}

Keywords: orphans' children, adapting in orphanage, stimulating environment, positive distraction

\section{INTRODUCTION}

The ongoing increasing growth of orphaned and abandoned children has proved a challenging problem. Recent estimates from the United Nations Children's Fund (UNICEF) indicated 153 million children worldwide, ranging from infants to teenagers, have lost one or both parents (Thabet et al., 2014). Experts have illuminated the number of orphaned children in the Gaza strip has nearly doubled in the last ten years due to the frequent wars, resulting in their growing up away from their homes in orphanages and, in the best cases, in their relatives' homes (Thabet et al., 2017). Researchers have unveiled orphaned children usually encounter many psychological issues stemming from losing parents and their homes' emotional warmth.

\section{Research Problem}

The research problem represents the following central question: How can architecture instrumentally alleviate orphaned children's psychological problems stemming from living in an orphanage.

\section{Research Objectives}

The research highlights architecture's role as a tool to improve orphan children's mental health while living in orphanages. The study aims to formulate design schemes to direct children home design and detail design interventions.

\section{ORPHAN PYSCHOLOGICAL PROBLEMS}

After losing a parent, children experience sadness, fear, depression, and lack of emotional support. The stress of losing parents can negatively impact children, fostering feelings of distrust, inferiority, embarrassment, humiliation, fear, and improper behavior (Naqshb et al., 2012, Tadesse et al., 2014). As a result of such issues, children who lose parents tend to exhibit risky behaviors, like drug abuse, abusive, and offender behavior (Saraswat, 2017). However, living in a sterile environment within orphanages aggravates and augments children's psychological outcomes. Experts have pointed out children living in orphanages face multiple hardships due to parental absence (Lassi et al., 2011; Rahman et al., 2012). Most orphans do not feel the true essence of love, for they do not experience the endearment, leadership, and parental advice (Engle et al., 2007), manifesting in lifelong implications (Sengendo and Nambi, 1997). In her survey carried out in children's homes in Delhi, Abhishek and Saraswat (2017) demonstrated self-discrimination was more prevalent in young children or individuals new to the orphanage system. These children sometimes sat alone, wept incessantly, missed mealtime, and isolated themselves, harming their wellbeing. Mental, behavioral, and attitude growth embodies the most prominent factors in children's overall development. 


\section{ORPHANAGE ENVIRONMENT AND CHILDREN'S PSYCHOLOGICAL NEEDS}

A primary reason for numerous developmental disorders found in children exposed to institutional settings involves the deprived atmosphere not providing sufficient experience to scaffold normal brain development (Roy, 2015). When children are forced to adapt to a new environment, they may demonstrate uncertainty, confusion, anxiety, and depression, leading to learning difficulties if not rectified (Saraswat, 2017) The pertinent question entails how orphanage design can help children overcome deep sadness and sorrow. As Van Meirs, the Amsterdam Orphanage founder, asserted, " On approaching a new environment, the child must enter it gladly; its outward appearance should ooze friendliness, beckoning to the child, as it were, to enter " (Roy, 2014: 26).

Orphan children should experience a positive setting. If orphanages do not accommodate a child's essential needs, this can adversely affect a child's mental and physical health, resulting in psychological issues (Marais et al., 2013). Easing such psychological outcomes among orphaned children will occur if the children home design incorporates juvenile attributes into the architecture (Roy, 2014). Many institutional-child care facilities protect the child but lack the true essence of home. In this space, a child should be eager to return and enjoy being in the presence of children collectively living and growing in a whimsical architectural environment designed specifically for them (Abebe, 2009).

\section{ALLEVIATING CHILD PSYCHOLOGICAL PROBLEMS THROUGH ORPHANAGES DESIGN}

As orphaned children must live away from their homes, the environment deprives them of the family ambiance. Hence, serious, careful attention should be given to the physical surroundings in which children are reared (Davies, 2011), including nurturing senses through orphanage architecture. The design should stimulate the senses and connect with nature, supporting children psychologically (Roy, 2014). Scholars have used three notions to tackle healing design and alleviate patient stress in healthcare institutions - stimulating environment, multi-sensory environment, and positive distraction.

\section{Stimulating Environment}

A stimulating environment aims to create an environment engaging the body, encouraging playful sensory exploration, and offering a seamless relationship with the site's natural environment. Stimulating the senses signals a child's brain, reinforcing learning neuronal networks. Space design insights the senses and interacting with the surroundings remains vital for child wellbeing and safe upbringing. Orphaned kids living in institutional care centers most likely do not enjoy the sensual wonders, for the setting lacks touch appeal, pleasant smells, and life beyond the institutional gates. As early childhood educators have professed, sensory stimuli remain significant. In a child's life, an individual can create significant resources to experience and consciously use all their senses. Sensory play in children's lives enhances cognitive growth, mental development, social skills, physical abilities, and communication skills. Childhood experiences form the future physical, mental and psychological behavior of people persisting into their adult lives. Adverse and negative development will harm the psychosocial wellbeing of children, as well as adults.

\section{Multi-sensory Environment}

A person uses one's five senses when the individual fully perceives the surroundings (Rhyl, 2009). Multi-sensory architecture aims to augment the settings' perceptions and feelings to build experientially, employing all human senses (Vermeersch and Heylighen, 2012). Steven Hall purported, "the way space feels, the sound and smell of these places, have equal weight to the way things look" (p. 6), where Pallasmaa mentioned, "every touching experience of architecture is multi-sensory; qualities of space, matter, and scale are measured equally by the eye, nose, skin, tongue, skeleton, and muscles” (Pallasmaa, 2012: 41).

\section{Positive Distraction}

Accordingly, and in the same context, positive distraction can be described as the "focus of this new research had the common theme of providing positive distraction, or the ability to allow the individual to shift focus from negative foci within the health environment to the more restorative aspects of the non-medical world “ (Shepley, 2006: S34). Positive distraction has been widely used in healthcare research as a tool to speed patient recovery. According to Shepley (2006: 36S), positive distraction incorporates design characteristics to foster recovery from stress in patients, visitors, and healthcare staff. Positive distraction can use design to help an orphanage overcome juvenile psychological problems. A person may be too easily distracted in an overstimulating environment, too highly aroused to think playfully and flexibly. However, several forms of positive distraction exist: art (including music and entertainment), access to nature, and social interaction.

\section{STIMULATING ENVIRONMENT, SENSORY ENVIRONMENT, AND POSITIVE DISTRACTION}

The three definitions demonstrate these themes significantly intersect, for they trigger user senses and attention to interact with the architectural surroundings to create positive feelings. However, positive distraction exemplifies a primary tool used when applying a multi-sensory architecture approach. Moreover, the stimulating environment incorporates positive distraction and a multisensory environment. Figure 1 shows the relation between these three themes. If children's spaces integrate surprise, unexpectedness, and ambiguity, the setting will fulfill the need for stimulation, positive distraction, and multi-sensory interaction with the environment. Generally, when designing places to activate positive distraction, external stimulation should remain moderate: not too much and not too little. 


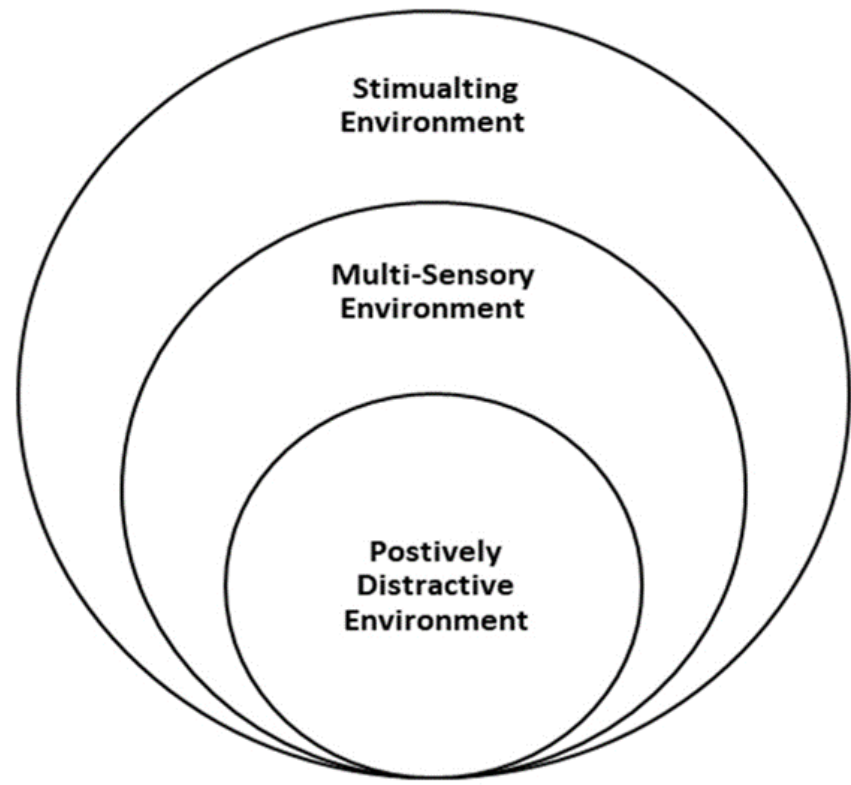

Figure 1. The Relationship between Stimulating Environment, Multi-Sensory Environment and Positive Environment

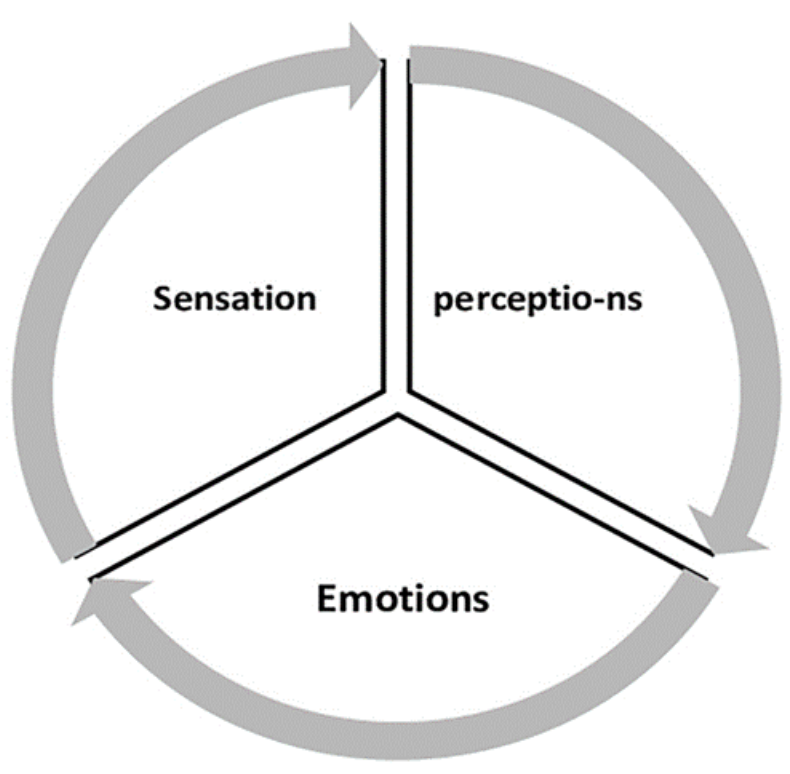

Figure 2. The three aspects of Stimulating environment

\section{ASPECTS OF STIMULATING ENVIRONMENT}

Various aspects can create a stimulating environment in an orphanage. An engaging setting as a design approach must include both the positive distraction and multi-sensory design. Hearing, touching, smell, and viewing embody the principal multi-sensory environment components, while inspiration and emotion form the most effective strategies to achieve positive distraction. Therefore, mapping out the chief elements of a stimulating environment requires putting them in three primary categories: senses, brain, and emotion, see Figure 2. Notably, these categories remain intertwined and interdependent.
Sensation / Aspects of Direct Environmental Influences on Senses

\section{Touching and texture}

Touch allows one to perceive barriers and distinctions between one's body and surroundings (Roy, 2014). This awareness remains central to the knowledge and assurance of one's existence. If children cannot become acquainted with this feeling, they become detached from the world around them, and any part of life includes the body. Different textured surfaces can create excellent sensory, cognitive, and interactive environments. It can also influence a person's perception of tastes, smells, sounds, and memories of past sensory experiences (Pallasmaa, 2012). Cold and hard building materials, such as steel, large sheets of glass, and aluminum, make buildings feel unfriendly; they typify machine products without life. Wood is touch-friendly, warm, and alter-tolerant, allowing for a wide range of moods, from a cozy enclosure to extensively glazed openness (Park, 2013).

\section{Sight and color, light and motion}

Color: Scholars examining color impact on mood have identified general disposition principles based on broad color ranges (Radwan, 2015). Color has the most robust, effective, and mystical influence in architecture. Color impression and the meaning it conveys primarily generates a mental mood or sensation supporting the space (Eiseman and Hickey, 1998; Meerwein et al., 2007). Concern about the environment's color design contributes to the relationship between children's cognitive, emotional, social development, and various settings. Color lets children garner a vibrant sensory experience. Brightly lit rooms are more exciting than dimly lit ones (Mehrabian, 1976). The warm spectrum (red, orange, and yellow) correlates with excitement and stimulation, while darker and more saturated colors from the end of the spectrum (dark, deep red) are more thrilling than softer and less saturated colors (Mehrabian and Russell, 1974).

Lighting: The principal concern in interior lighting entails providing appropriate visual comfort, but it has other health and wellbeing effects that warrant considering artificial lighting and daylight (Webb, 2006). Apart from vision, it also regulates the circadian rhythm of hormone secretions and body temperature affecting sleep/wake, alertness, and mood, actions. Additionally, solar radiation and daylight profoundly impact human physiology. Lighting affects children's perceptions and environmental reactions. Hence, the orphanage design should include a reasonable plan for openings (windows and doors) to allow daylight to enter. Also, colored lights can be used in various settings depending on the occasion. For instance, each room should control minimum and maximum lighting, depending on the interior space's purpose and usefulness (Reddyet al., 2012).

Motion: Moving things remain unpredictable, making them more exciting than static objects. Many ways exist to integrate animation into interior design, including projecting images, moving, kinetic sculptures, fountains, and mechanical novelties (Miller and Schmitt, 1985). Indirect illumination of aerial sculptures, and plighting plants create moving shadows and draw interest. Living creatures, such as fish, birds, cats, and other pets, can offer unforeseeable excitement, 
incorporating such objects into orphanages could keep children busy, engaged, and persistently entertained.

Hearing and Sounds: Healthy child growth often requires a diverse setting filled with sounds, especially language. Deficiencies or excesses can contribute to several problems (Kraftl, 2008). Involving the group with music illustrates another way of providing a pleasant sound atmosphere for orphaned children, as the musical atmosphere also gives them an opportunity, helping them forget their daily problems and sorrows. Musical training was initiated in an orphanage in Europe in the 17th century, where people from all over Europe would gather to enjoy chamber music performances. This practice has persisted in orphanages throughout Italy, for it has taught children discipline and stressed the importance of teamwork to accomplish a shared goal. This tradition's reappearance portrays these orphanage directors believed music helped soothe the grief, at times, overwhelming these children, who were robbed of their parents by tragedy or abandoned by poverty (Roy, 2014). Likewise, orphanages must consider incorporating this as a practice in their daily activities.

Smelling/Odor: Designers skillfully develop a unique visual environment. This method is quite fitting since humans are predominantly visual creatures. Perhaps because of the focus on vision, the other senses can be used successfully to enact unforgettable experiences and positive placeattachment. Hall (1966) suggested the perception of places associated with specific smells is much stronger than those identified with sights or sounds.

\section{PERCEPTION AND ASPECTS OF DIRECT ENVIRONMENTAL INFLUENCES ON PERCEPTIONS}

\section{Inspirational Displays}

Madi pointed out a monotonous environment diminishes the ability to think creatively (Maddi et al., 1962). Viewing artwork inspires thoughts. Painting can trigger emotions, perceptions, and other mental processes. Designers can personalize rooms with artwork, gather artifacts, and use other enticing design to help children generate many impressions.

\section{Releasing Thought/Openness and Spaciousness}

Some evidence of an association between movement and creative thoughts exists. Therefore, providing the orphanage with a creative place with sufficient floor space and floor covering fosters free-flowing and creative exercise. Space may also be used for yoga, meditation, and other forms of relaxation. Spacious places give a sense of openness, releasing thought from inhibitions and restrictions. Design strategies should make rooms appear larger than they are to create this feeling (Miller and Schlmitt, 1985).
Emotion and Environmental Aspects with a Direct Psychological Influence

\section{Space and form}

Several researchers have provided evidence on the impact of different forms of thoughts and feelings. For example, spaces composed of strong geometry, such as triangles, pyramids, or any other forms with right angles, motivate people. On the contrary, curves and smooth circular forms have no sharp edges. Such forms are more suitable for children who are still developing mentally. (Bower et al., 2019). Psychologists have unmasked the symbolic significance of standard shapes and figures. Form and space's psychological effect on users poses an essential issue for architects, as people remain emotionally engaged in their surroundings (Gifford, 2007; Manzo, 2003, Reddy et al., 2012). Taking that into consideration will help create a more meaningful and stimulating setting. The following forms elicit the following meanings and feelings:

- The circle symbolizes connection, movement, safety, and perfection, illustrating femininity: warmth, comfort, sensuality, community, wholeness, and love.

- The square represents order, logic, containment, and security, depicting masculinity: power, strength, determination, and stability.

- The triangle portrays energy, power, balance, law, science, and religion, demonstrating masculinity: strength, aggression, and dynamic movement.

However, color influences form symbolization. Therefore, particular attention should be given to the colors used in juvenile settings; for example, pastel yellow conveys a sunny, neighborly, and delicacy feeling. The message in the inner space invigorates an individual brightly and comfortably. Red is thrilling, enthusiastic, provocative, blazing, and decadent, sending firm, propulsive, overwhelming vibes. Green is adapting, usual, quiet (Radwan, 2015).

The invisible characteristics of forms also play a crucial role in design for children. Proportions can determine use and usability; one cannot feel comfortable in a room with an overwhelming high ceiling presence or when the ceiling is too low. The scale is also a profound factor in design, proportional to age and growth (Vartanian et al., 2015); thus, designing should differ among adults and children. Spatial qualities affect children's moods and emotions. However, several experts have depicted familiar objects encountered on a larger-than-normal scale can elicit immediate emotional due to unexpectedness (Banaei et al., 2017; Gifford 2007). Mehrabian and Russell (1974) suggested elements encountered with large-scale design or a smaller-than-normal size can be just as surprising and exciting, but perhaps not as jolting to the senses. The activity placed in a specified area will decide the spatial aesthetics to accommodate the audience and the program. For instance, indoor play areas entail common spaces inside an orphanage; therefore, the colors, scale, proportion, and forms must match the age group, the room's size, and emotional effect on children (Roy, 2014). 


\section{In between spaces}

The journey from one space to another remains vital to child wellbeing. The orphanage must have no endless corridors and gateways where the child can be lost. The journey must allow children to travel from one space to another with ease and no hesitation, as it can influence curiosity and the decision to take the next step in the journey (Kozlovsky, 2016).

\section{Spaces of rest}

Rest in a children's home can assume several forms. Apart from their sleeping corners, solitary confinement spaces remain essential to a child's proper psychological development. Bedrooms engender intimate realms; but, attics, cellars, storerooms, and garden sheds contain secret items to inspire imaginative play; however, they instigate various moods. Sheridan Bartlett (1997) postulated if a house were designed exclusively for children, the home would consist of an attic and blinds, ample closets and narrow doors, cubicles, and alcoves. These spaces do not require imaginative thinking; children will turn essential elements into new whimsical designs within an architectural setting. Ledges, landings, and deep windows comprise architectural symbols offering children the space they need for perfect solitary play. Likewise, places of rest can also exist outdoors. Yards, forests, grounds cut-outs, climbing boulders, tree-lined swings, tree-houses, and play sand typify a few outdoor features children enjoy. If these elements are genuinely understood and integrated into orphaned children's home, they will sufficiently stimulate troubled minds and emotionally and physically nourish them.

\section{Viewing gardens}

Children cannot avoid the extraordinary sensory diversity and variability of the natural world (Ulrich, 1991). Also, researchers in healthcare have professed nature has positively affected people, controlling stress and diverting annoyance. In recent studies of stress and its harmful health effects, research participants were displayed pictures of various items; in most cases, they instantly calmed when presented with nature pictures, demonstrating reduced stress hormones, blood pressure, respiration rate, and brain activity. Similarly, healing gardens can improve rest and sleep, state of mind, and pain tolerance. As Eliovson (1978) claimed, these gardens' primary goal was to create a tranquil view from an adjoining room, so people looking outside relaxed and immersed themselves in thought.

Elements of child's garden:

- Child-friendly entry

- Comfortable space for staff and parents

- Many options to interact with nature through senses and hands-on activities

- Plant a garden and harvest

- Universal Accessibility

- Multi-purpose setting for activities, social gatherings

- Shade

- Plants and trees dropping leaves and twigs

- Seeds and stones

- Hills

- Storage, potting shed

- Fun signage

\section{DISCUSSIONS}

The reviewed literature suggesting design strategies alleviate the psychological problems orphan children living in institutional home care encounter. A stimulating environment extensively and specifically guides design solutions to achieve an engaging setting. However, a comprehensive framework can connect the psychological issues with the required design features. Such a structure should not restrict new design solutions to nurture children in institutional programs. Table 1 outlines these facets.

\section{CONCLUSION}

This research developed a scheme to direct the design of children's homes, describing design interventions. The study linked the most common psychological problems of orphaned children with architectural and interior design. The research also drew upon literature to develop categories for creating a stimulating environment as a design approach. The engaging environment embodies a collective multi-dimensional

Table 1. Orphan Children Psychological Problems and the Needed Design Interventions

\begin{tabular}{|c|c|c|c|}
\hline $\begin{array}{l}\text { Psychological } \\
\text { Issue Addressed }\end{array}$ & Requirement & Architectural level & Design interventions \\
\hline Sadness & $\begin{array}{l}\text { Creating a stimulating, } \\
\text { positively distracting } \\
\text { environment }\end{array}$ & $\begin{array}{l}\text { Provide healing gardens, large windows for } \\
\text { viewing nature, playgrounds, and visiting } \\
\text { spaces for friends and family. }\end{array}$ & $\begin{array}{l}\text { Colorful design uses warm colors, avoids } \\
\text { large scales unless intended for artistic } \\
\text { purposes, like interior fountains and } \\
\text { planting, vivid sensory experience within } \\
\text { interior spaces (birds, vegetation, doormat). }\end{array}$ \\
\hline Depression & $\begin{array}{l}\text { Enhancing self-esteem } \\
\text { creating a stimulating and } \\
\text { colorful setting }\end{array}$ & $\begin{array}{l}\text { Inspirational building form, intelligibility } \\
\text { spaces layout using large windows for daylight } \\
\text { and viewing nature, healing gardens, } \\
\text { playgrounds, and workshops for artworks, }\end{array}$ & $\begin{array}{l}\text { Display panels for personal achievements } \\
\text { and awards. use artworks, red, yellow, orange } \\
\text { colors, and interior gardening }\end{array}$ \\
\hline Fear & $\begin{array}{l}\text { Promoting the feeling of } \\
\text { security, creating a positively } \\
\text { distractive surrounding, }\end{array}$ & Friendly, colorful & \\
\hline Social Isolation & Stimulating environment & $\begin{array}{l}\text { Building design should influence social } \\
\text { opportunities and interactions }\end{array}$ & \\
\hline
\end{tabular}


experience, triggering senses, brain, and emotion. These dimensions remain complex and intertwined. Through the proposed scheme, the researcher linked these components with design elements and features. This research explored how architectural design can alleviate orphaned children's psychological problems, such as social isolation, depression, and fear resulting from losing parents and moving to a new setting away from their home. Further research could assess whether the architecture diminishes other psychological issues manifesting in orphaned children, such as fragmented identity, violence, and crime.

Author contributions: All co-authors have involved in all stages of this study while preparing the final version. They all agree with the results and conclusions.

Funding: No external funding is received for this article.

Declaration of interest: The authors declare that they have no competing interests.

Ethics approval and consent to participate: Not applicable.

Availability of data and materials: All data generated or analyzed during this study are available for sharing when appropriate request is directed to corresponding author.

\section{REFERENCES}

Abebe, T. (2009). Orphanhood, poverty, and the care dilemma: Review of global policy trends. Social Work \& Society, 7(1), 70-85. Available at: https://www.semanticscholar.org/ paper/Orphanhood\%2C-Poverty-and-the-Care-Dilemma \%3A-Review-of-Abebe/bbc75624835e3665226e2d092a6e1 14198d80a1f

Balters, S., 2011. AD Classics: Amsterdam Orphanage/ Aldo Van Eyck. Available at: https:/www.archdaily.com/ 151566/ad-classics-amsterdam-orphanage-aldo-van-eyck (Accessed: 13 September 2020).

Banaei, M., Hatami, J., Yazdanfar, A. and Gramann, K. (2017). Walking through architectural spaces: the impact of interior forms on human brain dynamics. Frontiers in Human Neuroscience, 11, 477. https://doi.org/10.3389/ fnhum.2017.00477

Bower, I., Tucker, R. and Enticott, P. G. (2019). Impact of built environment design on emotion measured via neurophysiological correlates and subjective indicators: A systematic review. Journal of Environmental Psychology, 66, 1-11. https://doi.org/10.1016/j.jenvp.2019.101344

Children's Defense Fund. (2014). State of America's children. Available at: http://www.childrensdefense.org/childresearch-data-publications/data/2014-soac.pdf

Davies, D. (2011). Child development: A practitioner's guide (3rd ed.). Guilford Press.

Eiseman, L. and Hickey, R. (1998). Colors for your every mood: Discover your true decorating colors. Capital Books.

Eliovson, S. (1978). c_A new exhibition ground for the wild flowers of South Africa. Veld and Flora, 91-93. Available at: https://journals.co.za/docserver/fulltext/veld/64/3/762.pd f?expires $=1607785779$ \&id=id \&accname $=$ guest $\&$ checksu $\mathrm{m}=\mathrm{DAC} 776437 \mathrm{AB} 405 \mathrm{D} 415258 \mathrm{~F} 3 \mathrm{AAOACD} 413$

Gifford, R. (2007). Environmental psychology: Principles and practice. Optimal Books.
Hall, E. T. (1966). The hidden dimension (Vol. 609). Doubleday.

Kozlovsky, R. (2016). The architectures of childhood: Children, modern architecture, and reconstruction in postwar England. Routledge. https://doi.org/10.4324/9781315612560

Kraftl, P. (2008). Young people, hope, and childhood-hope. Space and Culture, 11(2), 81-92. https://doi.org/10.1177/ 1206331208315930

Lassi, Z. S., Mahmud, S., Syed, E. U. and Janjua, N. Z. (2011). Behavioral problems among children living in orphanage facilities of Karachi, Pakistan: Comparison of children in an SOS Village with those in conventional orphanages. Social Psychiatry and Psychiatric epidemiology, 46(8), 787-796. https://doi.org/10.1007/s00127-010-0248-5

Maddi, S. R., Charlens, A. M., Maddi, D. A. and Smith, A. J. (1962). Effects of monotony and novelty on imaginative productions. Journal of Personality, 30(4), 513-527. https://doi.org/10.1111/j.1467-6494.1962.tb01686.x

Manzo, L. C. (2003). Beyond house and haven: Toward a revisioning of emotional relationships with places. Journal of Environmental Psychology, 23(1), 47-61. https://doi.org/10.1016/S0272-4944(02)00074-9

Marais, L., Sharp, C., Pappin, M., Lenka, M., Cloete, J., Skinner, D. and Serekoane, J. (2013). Housing conditions and mental health of orphans in South Africa. Health \& Place, 24, 2329. https://doi.org/10.1016/j.healthplace.2013.08.004

Meerwein, G., Rodeck, B. and Mahnke, F. H. (2007). Color Communication in Architectural Space. Basel: Birkhauser Verlag. https://doi.org/10.1007/978-3-7643-8286-5

Mehrabian, A. (1976). Public places and private spaces: The psychology of work. Play and Living Environments.

Mehrabian, A. and Russell, J. A. (1974a). An approach to environmental psychology. The MIT Press.

Mehrabian, A. and Russell, J. A. (1974b). The basic emotional impact of environments. Perceptual and Motor Skills, 38(1), 283-301. https://doi.org/10.2466/pms.1974.38.1.283

Miller, S. and Schlitt, J. K. (1985). Interior space: Design concepts for personal needs. Praeger Publishers.

Naqshb, M. M., Sehgal, R. and ul Hassan, F. (2012). Orphans in orphanages of Kashmir and their psychological problems. International NGO Journal, 7(3), 55-63. https://doi.org/10.5897/INGOJ12.016

Pallasmaa, J. (2012). The eyes of the skin: Architecture and the senses. John Wiley \& Sons.

Park, K. H. P. (2013). Human figure of furniture. Rochester Institute of Technology.

Qahtani, L. A. I. L. A. (2015). The correlation between orphanages' interior design and children's psychosocial adaptation. International Journal of Research in Humanities, Arts and Literature, 3(2), 1-20.

Radwan, A. H. (2015). Color in architecture is it just an aesthetic value or a true human need? Int Journal of English Research Technology, 4, 523-533. Available at: https://www.ijert.org/research/color-in-architecture-is-itjust-an-aesthetic-value-or-a-true-human-needIJERTV4IS120587.pdf 
Rahman, W., Mullick, M. S. I., Pathan, M. A. S., Chowdhury, N. F., Shahidullah, M., Ahmed, H., ... and Rahman, F. (2012). Prevalence of behavioral and emotional disorders among the orphans and factors associated with these disorders. Bangabandhu Sheikh Mujib Medical University Journal, 5(1), 29-34. https://doi.org/10.3329/bsmmuj.v5i1.10997

Reddy, S. M., Chakrabarti, D. and Karmakar, S. (2012). Emotion and interior space design: An ergonomic perspective. Work, 41(Supplement 1), 1072-1078. https://doi.org/ 10.3233/WOR-2012-0284-1072

Roy, N. (2015). I'm Still a Kid!: A Proposal for Improving Orphanages through the Integration of Nature, Nurture \& The Senses (Doctoral dissertation, Carleton University).

Ryhl, C. (2009). Architecture for the senses. Inclusive Buildings, Products \& Services: Challenges in Universal Design, 105.

Saraswat, A. and Unisa, S. (2017). An in-depth study of psychosocial distress among orphan and vulnerable children living in institutional care in New Delhi, India, and their coping mechanisms. Available at: https://bettercare network.org/sites/default/files/Psychosocial\%20distress\% 20and\%20coping\%20mechanism\%20of\%200rphan\%20Ch ildren-\%20Saraswat\%20and\%20Unisa.pdf

Sengendo, J. and Nambi, J. (1997). The psychological effect of orphanhood: a study of orphans in Rakai district. Health Transition Review, 105-124. Available at: https://pubmed.ncbi.nlm.nih.gov/10169639/

Shepley, M. M. (2006). The role of positive distraction in neonatal intensive care unit settings. Journal of Perinatology, 26(3), S34-S37. https://doi.org/10.1038/ sj.jp.7211584

Tadesse, S., Dereje, F. and Belay, M. (2014). Psychosocial wellbeing of orphan and vulnerable children at orphanages in Gondar Town, North West Ethiopia. Journal of Public Health and Epidemiology, 6(10), 293-301. https://doi.org/10.5897/JPHE2014.0648
Thabet, A. A., Elheloub, M. W. and Vostanis, P. (2017). Prevalence of PTSD, depression, and anxiety among orphaned children in the Gaza Strip. Early Childhood Pediatrics, 5, 159-169. Available at: https://www.semantic scholar.org/paper/Prevalence-of-PTSD\%2C-Depression \%2C-and-Anxiety-Among-Thabet-Elhelou/8eb1f31c837f7 ad3ca289b417928f327a6497f97

Ulrich, R. S. (1991). Effects of interior design on wellness: Theory and recent scientific research. Journal of Health Care Interior Design, 3(1), 97-109. Available at: https://www.semanticscholar.org/paper/Effects-ofinterior-design-on-wellness\%3A-theory-andUlrich/6a241e8975b7ac56d0c771633fb5411c62c8e14f

Vartanian, O., Navarrete, G., Chatterjee, A., Fich, L. B., Gonzalez-Mora, J. L., Leder, H., Modrono, C., Nadal, N., Rostrup, N. and Skov, M. (2015). Architectural design and the brain: Effects of ceiling height and perceived enclosure on beauty judgments and approach-avoidance decisions. Journal of Environmental Psychology, 41, 10-18. https://doi.org/10.1016/j.jenvp.2014.11.006

Vermeersch, P. W. and Heylighen, A. (2012). Blindness and multi-sensoriality in architecture. The case of Carlos Mourão Pereira. The Place of Research, the Research of Place, 393-400. Available at: https://limo.libis.be/primoexplore/fulldisplay?docid=LIRIAS1713893 \&context=L\&vi $\mathrm{d}=$ Lirias \&search_scope=Lirias \&tab=default_tab\&lang $=$ en US \& fromSitemap=1

Webb, A. R. (2006). Considerations for lighting in the built environment: Non-visual effects of light. Energy and Buildings, 38(7), 721-727. https://doi.org/10.1016/ j.enbuild.2006.03.004 